\title{
Note of clarification of data in the paper entitled association between BRIPI (BACH1) polymorphisms and breast cancer risk
}

\author{
Yadong Wang ${ }^{1}$ Haiyan Yang ${ }^{2} \cdot$ Haiyu Wang ${ }^{1}$
}

Received: 26 February 2015/Accepted: 10 March 2015/Published online: 18 March 2015

(C) Springer Science+Business Media New York 2015

\begin{abstract}
With great interest, we read the recent article entitled "Association between BRIPI (BACHI) polymorphisms and breast cancer risk: a meta-analysis" published online in Pabalan et al. (Breast Cancer Res Treat 137:553-558, 2013). This article suggests that overall summary estimates imply no associations but suggest susceptibility among carriers of the $C 47 G$ polymorphism and Pro-Ser genotype in premenopausal women. The result is encouraging. Nevertheless, several key issues in this meta-analysis are worth noticing.
\end{abstract}

Keywords BRIPI - Polymorphism - Breast cancer . Risk $\cdot$ Meta-analysis

Recently, we read with great interest the article entitled "Association between BRIPI (BACHI) polymorphisms and breast cancer risk: a meta-analysis" published online in Breast Cancer Res Treat, 2013, 137: 553-558 [1]. Pabalan et al. conducted a meta-analysis to examine the association between the Pro919Ser polymorphisms in the BRCA1 interacting protein 1 (BRIPl) gene and breast cancer risk on the basis of eight case-control studies with 5122 cases and 5735 controls. They also studied the risk associated with the two additional BRIPI C47G and G64A polymorphisms and breast cancer risk on the basis of 1539 cases and 1183 controls, and 667 cases and 782 controls, respectively. The

Yadong Wang

wangyd76@163.com

1 Department of Toxicology, Henan Center for Disease Control and Prevention, No.105 of South Nongye Road, Zhengzhou 450016, China

2 Department of Epidemiology, School of Public Health, Zhengzhou University, Zhengzhou 450001, China authors found that the association was lacking between the Pro919Ser polymorphisms and breast cancer risk in overall analysis [odds ratio (OR) 0.98-1.02], materially unchanged when confined to subjects of European ancestry (OR $0.96-1.03$ ) or even in the high-powered studies (OR $0.97-1.03)$. In the menopausal subgroups, premenopausal women followed the null pattern (OR 0.94-0.98) for the Pro and Ser allele contrasts, but not for the Pro-Ser genotype comparison where significant increased risk was observed (OR $1.39, P=0.002$ ). The $G 64 A$ polymorphism effects were essentially null (OR $0.90-0.98$ ), but $C 47 G$ was found to confer nonsignificantly increased risk under all genetic models (OR 1.27-1.40). It is an interesting study.

Nevertheless, careful examinations of the data provided by Pabalan et al. [1] (shown in Table 1 in their original text) reveal four key issues that are worth noticing. Firstly, the data reported by Pabalan et al. [1] for the study of Rutter et al. [2] did not seem in line with the data provided by Rutter et al. [2] in their original publication. The numbers reported by Rutter et al. for cases and controls, are 58 and 30, respectively [2]. Interestingly enough, after carefully examining the data reported by Pabalan et al. [1], the numbers are 116 in cases and 60 in controls, respectively. Secondly, Rutter et al. [2] also reported the association of BRIP1 G64A polymorphisms with breast cancer risk. But the data were not included in Pabalan et al's study [1]. Thirdly, one eligible paper [3] focusing on the association of BRIP1 G64A polymorphisms with breast cancer risk was not included in Pabalan et al's study [1]. Fourthly, one eligible paper [4] focusing on the association of BRIP1 Pro919Ser polymorphisms with breast cancer risk was not included in Pabalan et al's study [1]. Therefore, the conclusions by Pabalan et al. [1] are not entirely reliable. It is required to clarify the association between BRIPI polymorphisms and the risk of breast cancer comprehensively 
Table 1 Characteristics of the included studies associating BRIP1 polymorphisms in breast cancer

\begin{tabular}{|c|c|c|c|c|c|c|c|c|c|c|}
\hline \multirow[t]{2}{*}{ First author } & \multirow[t]{2}{*}{ Year } & \multirow[t]{2}{*}{ Country } & \multirow[t]{2}{*}{ Source of control } & \multicolumn{2}{|c|}{ Pro919Ser } & \multicolumn{2}{|l|}{$C 47 G$} & \multicolumn{2}{|l|}{$G 64 A$} & \multirow[t]{2}{*}{$P$ value of $\mathrm{HWE}^{\mathrm{a}}$} \\
\hline & & & & Cases & Controls & Cases & Controls & Cases & Controls & \\
\hline Loizidou [4] & 2009 & Cyprus & $\mathrm{PB}$ & 1108 & 1170 & & & & & 0.24 \\
\hline Rutter [2] & 2003 & USA & $\mathrm{PB}$ & 58 & 30 & 58 & 29 & 58 & 30 & 0.88 \\
\hline Garcia-closas [5] & 2006 & USA & PB & 1596 & 1254 & 1327 & 1056 & & & 0.27 \\
\hline Guenard [6] & 2008 & Canada & $\mathrm{PB}$ & 96 & 70 & 96 & 69 & 96 & 70 & 0.69 \\
\hline Seal [7] & 2006 & USA and Poland & PB & 1212 & 2081 & & & & & 0.34 \\
\hline Vahteristo [8] & 2006 & Finland & $\mathrm{PB}$ & 866 & 731 & & & & & 0.32 \\
\hline Frank [9] & 2007 & Germany & $\mathrm{PB}$ & 571 & 712 & & & 571 & 712 & 0.37 \\
\hline Silvestri [10] & 2011 & Italy & PB & 97 & 203 & & & & & 0.85 \\
\hline Song [3] & 2007 & England & PB & & & & & 2170 & 2264 & \\
\hline Huo [11] & 2009 & China & $\mathrm{PB}$ & 568 & 624 & & & & & 0.36 \\
\hline Ren [12] & 2013 & China & $\mathrm{HB}$ & 319 & 306 & & & 319 & 305 & 0.61 \\
\hline
\end{tabular}

$P B$ population-based control, $H B$ hospital-based control, $H W E$ Hardy-Weinberg equilibrium

${ }^{\text {a }}$ Based on the number of controls in the Pro919Ser polymorphism

and objectively. We re-evaluated this association by performing an updated meta-analysis on the basis of a total of ten studies with 6491 cases and 7181 controls for Pro919Ser, three studies with 1481 cases and 1154 controls for $C 47 G$ and five studies with 3214 cases and 3381 controls for $G 64 A$. Further subgroup analysis was also conducted in this study stratified by source of control and ethnicity. In addition, cumulative meta-analysis was performed to investigate the tendency of results by accumulating single study year by year, which could be used to determine whether new relevant studies are needed or not. We believe that our results will provide objective and comprehensive evidence for the association between $B R I P 1$ polymorphisms and breast cancer risk.
Table 1 listed the general information of selected studies in this meta-analysis. Table 2 listed the summary odds ratios of the association between BRIPI polymorphisms and breast cancer risk. Overall, we did not observe significant association between BRIP1 Pro919Ser polymorphisms and breast cancer risk under the genetic model of Ser-allele versus Pro-allele $\quad(\mathrm{OR}=0.99, \quad 95 \%$ CI 0.97-1.01) (Fig. 1a). We did not observe the association of $B R I P 1 C 47 G$ polymorphisms with breast cancer risk under the genetic model of $G$-allele versus $C$-allele ( $\mathrm{OR}=1.02$, $95 \%$ CI 0.99-1.05) (Fig. 1b). We also did not observe the association of BRIPI G64A polymorphisms with breast cancer risk under the genetic model of $A$-allele versus $G$ allele $(\mathrm{OR}=0.99,95 \%$ CI $0.97-1.02)$ (Fig. 1c). The

Table 2 Summary effects of BRIP1 polymorphisms in breast cancer

\begin{tabular}{|c|c|c|c|c|c|c|c|c|c|c|c|}
\hline \multirow[t]{2}{*}{ Genetic model } & \multirow[t]{2}{*}{ Cases/controls } & \multicolumn{2}{|c|}{ Heterogeneity test } & \multirow[t]{2}{*}{ Summary OR (95 \% CI) } & \multicolumn{2}{|c|}{ Hypothesis test } & \multirow[t]{2}{*}{$d f$} & \multicolumn{2}{|c|}{ Begg's test } & \multicolumn{2}{|c|}{ Egger's test } \\
\hline & & $Q$ & $P$ & & $z$ & $P$ & & $z$ & $P$ & $t$ & $P$ \\
\hline \multicolumn{12}{|c|}{ Pro919Ser: Ser-allele versus Pro-allele } \\
\hline Overall & $6491 / 7181$ & 5.00 & 0.834 & $0.99(0.97-1.01)$ & 0.89 & 0.372 & 9 & 2.15 & 0.032 & 1.93 & 0.090 \\
\hline \multicolumn{12}{|l|}{ Stratified by ethnicity } \\
\hline European only & $5604 / 6251$ & 1.70 & 0.974 & $0.99(0.97-1.02)$ & 0.45 & 0.651 & 7 & 1.36 & 0.174 & 1.73 & 0.135 \\
\hline \multicolumn{12}{|c|}{ Stratified by source of control } \\
\hline Population-based control & $6172 / 6875$ & 1.70 & 0.989 & $1.00(0.98-1.02)$ & 0.49 & 0.628 & 8 & 1.56 & 0.118 & 1.85 & 0.108 \\
\hline \multicolumn{12}{|c|}{$C 47 G$ : $G$-allele versus $C$-allele } \\
\hline Overall & $1481 / 1154$ & 4.08 & 0.130 & $1.02(0.99-1.05)$ & 1.12 & 0.261 & 2 & 1.04 & 0.296 & 2.31 & 0.260 \\
\hline \multicolumn{12}{|c|}{$G 64 A$ : $A$-allele versus $G$-allele } \\
\hline Overall & $3214 / 3381$ & 4.68 & 0.322 & $0.99(0.97-1.02)$ & 0.35 & 0.724 & 4 & 0.24 & 1.000 & 0.55 & 0.619 \\
\hline
\end{tabular}

$O R$ odds ratio, $C I$ confidence interval 


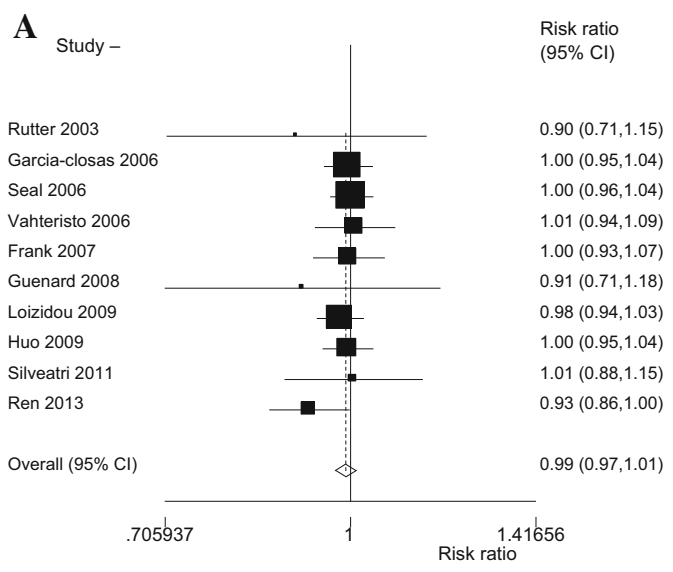

B

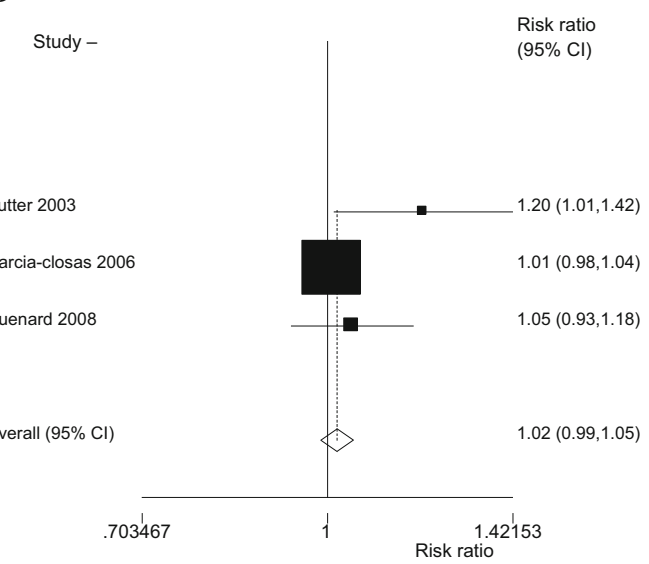

$\%$ Weight

C

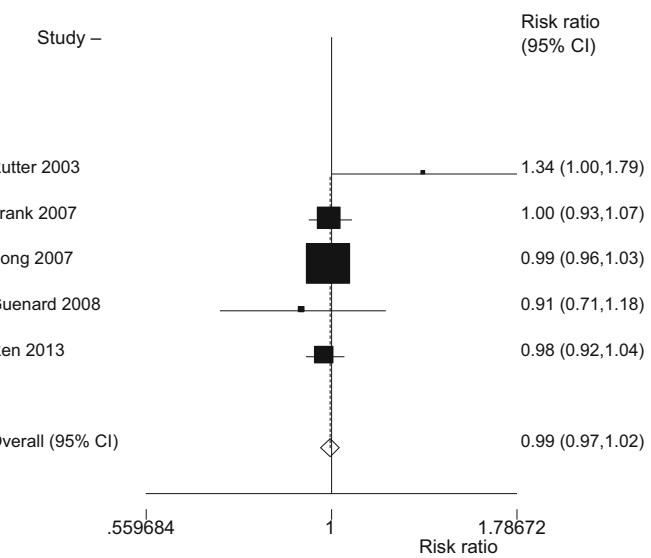

Fig. 1 Forest plots for the odds ratio of the association between BRIP1 polymorphisms and breast cancer risk (a Ser-allele vs. Proallele of $\operatorname{Pro} 919 \mathrm{Ser}$; b $G$-allele vs. $C$-allele of $C 47 G$; $\mathbf{c} A$-allele vs. $G$ allele of $G 64 A$ )

cumulative meta-analysis accumulated the studies in accordance with the year of publications and the results showed that there was still no significant association between BRIPI polymorphisms and breast cancer risk under allele models, the cumulative ORs were 0.99 with $95 \%$ CI 0.93-1.03 for Pro919Ser, 1.07 with $95 \%$ CI 0.95-1.22 for

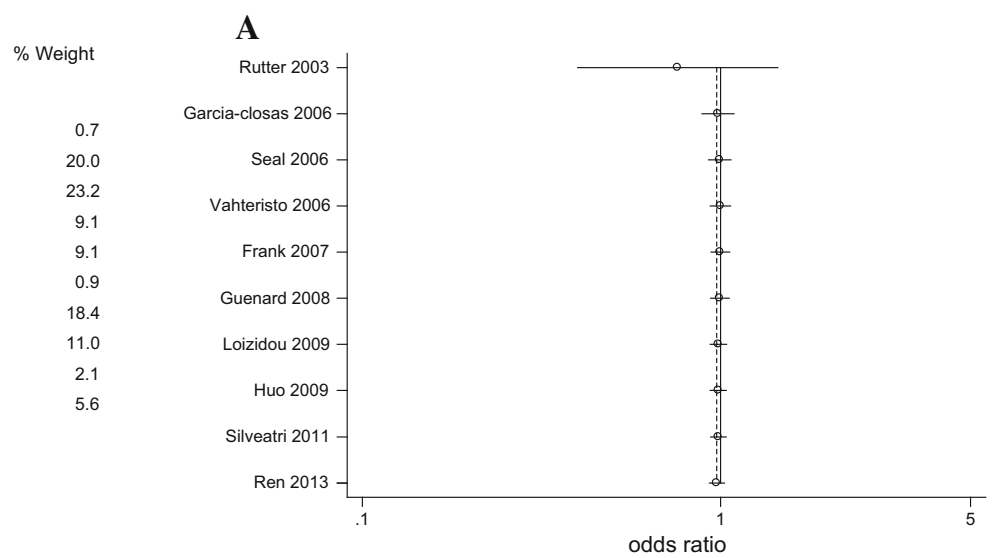

B

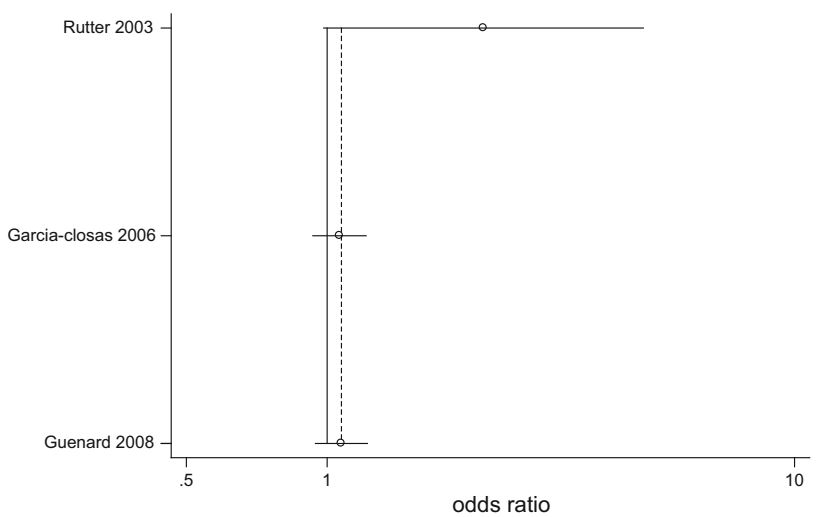

C

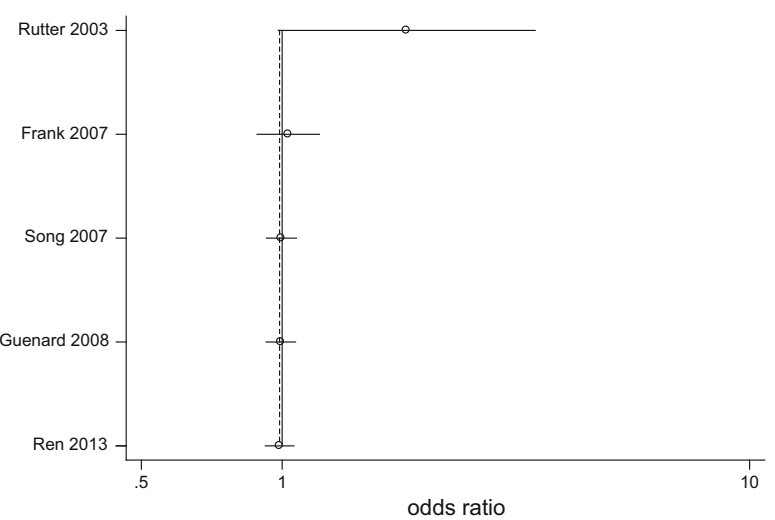

Fig. 2 Cumulative meta-analysis for the association between BRIPI polymorphisms and breast cancer risk (a Ser-allele vs. Pro-allele of Pro919Ser; b $G$-allele vs. $C$-allele of $C 47 G$; c $A$-allele vs. $G$-allele of G64A)

$C 47 G$ and 0.99 with $95 \%$ CI $0.92-1.06$ for $G 64 A$, respectively (Fig. 2a, b, c). In subgroup analysis by source of control, we did not observe a significant association between BRIP1 Pro919Ser polymorphisms and breast cancer under the allele model of Ser-allele versus Pro-allele on the basis of population-based controls $(\mathrm{OR}=1.00,95 \% \mathrm{CI}$ 0.98-1.02) (Table 2). We did not observe any association between BRIPl Pro919Ser polymorphisms and breast 
cancer risk among Europeans when stratified by ethnicity (Table 2).

The shape of funnel plots seemed to be approximately symmetrical among total population (Fig. 3a, b, c). Egger's test and Begg's test suggested that there was no obvious publication bias in this meta-analysis excerpt in the model

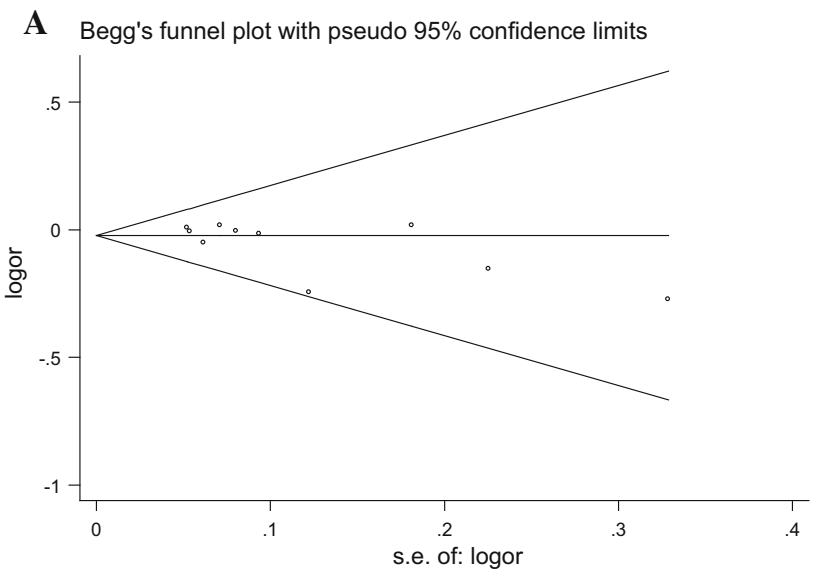

B Begg's funnel plot with pseudo $95 \%$ confidence limits

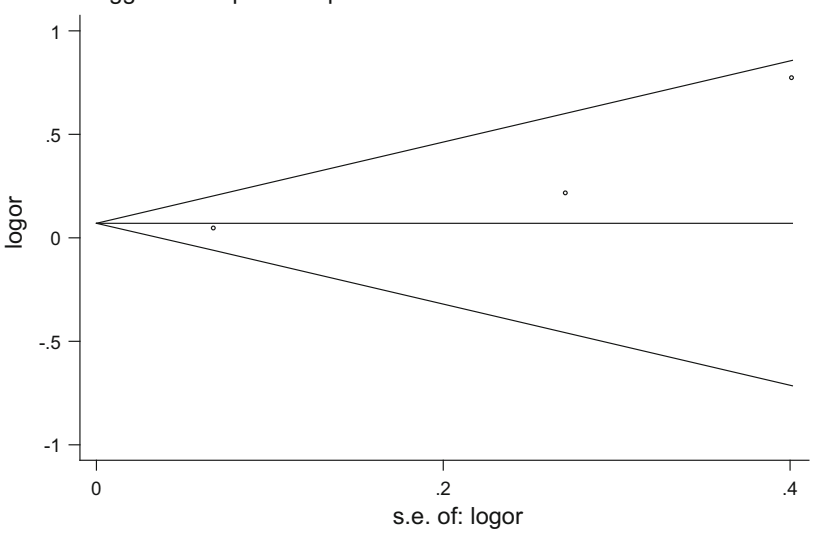

C Begg's funnel plot with pseudo $95 \%$ confidence limits

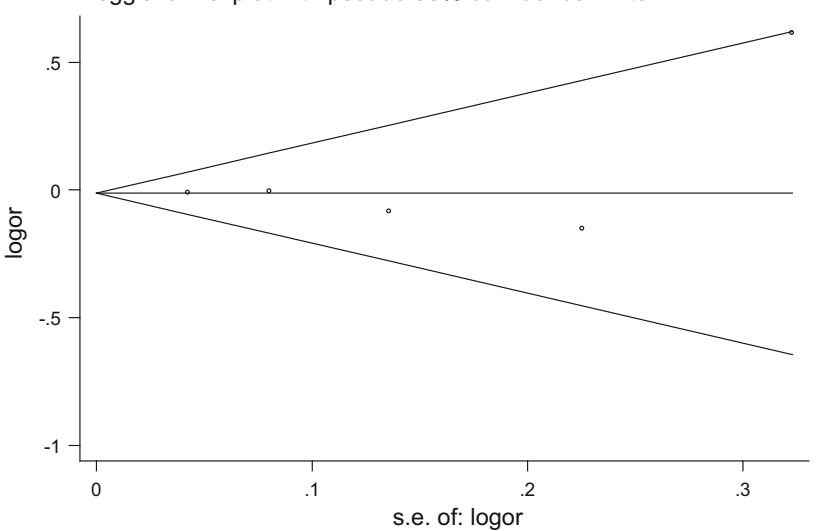

Fig. 3 Funnel plots for the association between BRIP1 polymorphisms and breast cancer risk (a Ser-allele vs. Pro-allele of Pro919Ser; b $G$-allele vs. $C$-allele of $C 47 G$; c $A$-allele vs. $G$-allele of $G 64 A$ ) of Ser-allele versus Pro-allele (Table 2). To evaluate the stability of the results of this current meta-analysis, a sensitivity analysis was conducted through sequentially removing each individual study. The sensitivity analysis showed that our results were robust and were not influenced by any single study (Fig. 4a, b, c).
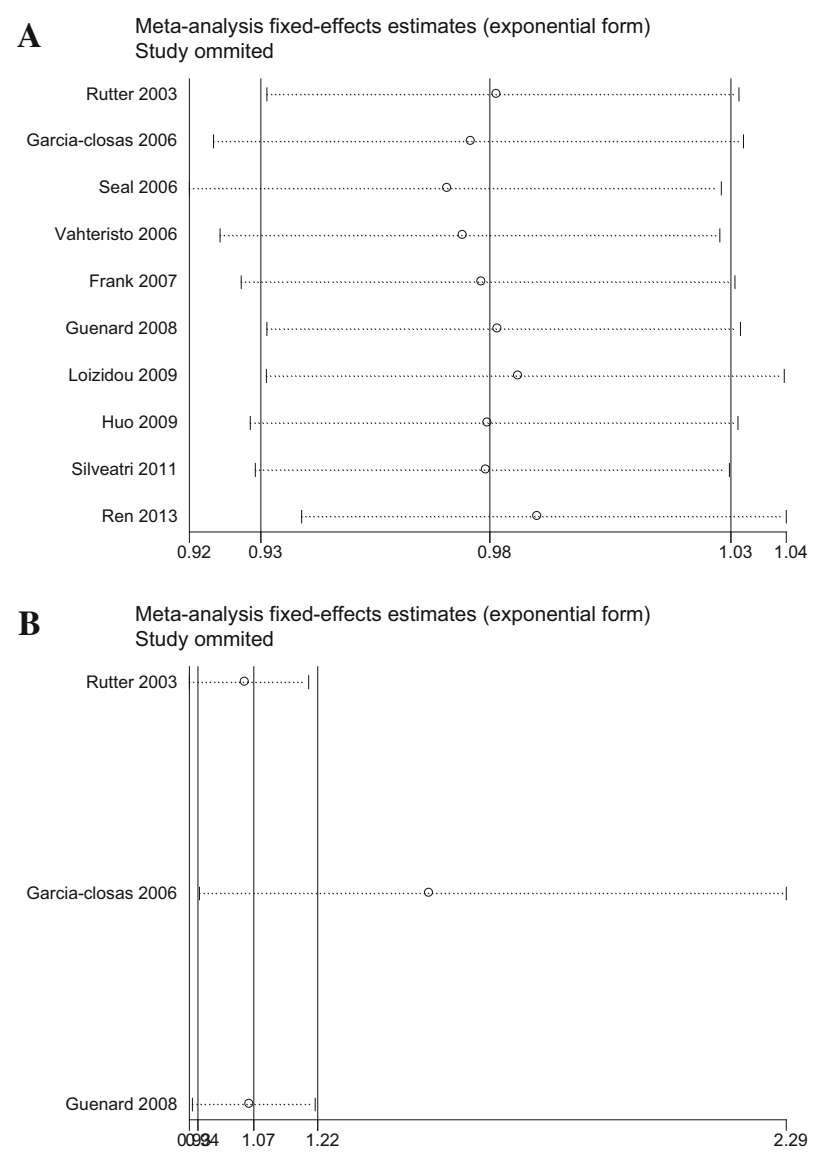

Meta-analysis fixed-effects estimates (exponential form)
Study ommited

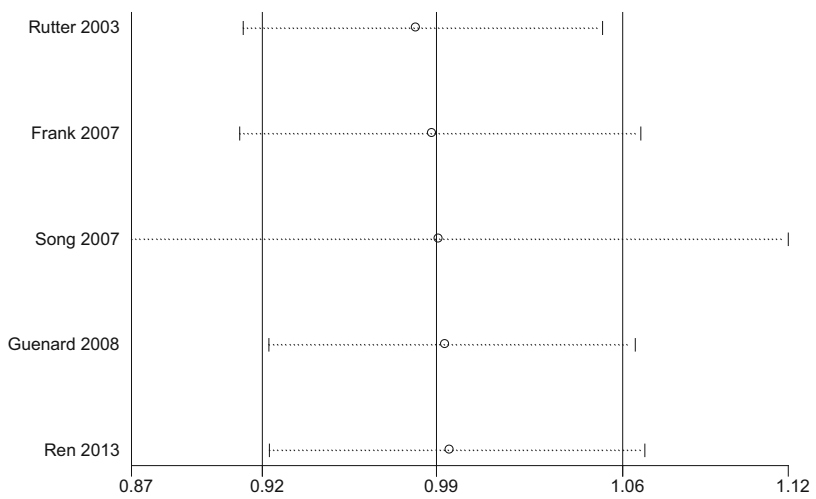

Fig. 4 Sensitivity analysis for the association between BRIPI polymorphisms and breast cancer risk (a Ser-allele vs. Pro-allele of Pro919Ser; b $G$-allele vs. $C$-allele of $C 47 G$; c $A$-allele vs. $G$-allele of G64A) 
In conclusion, the results of the study by Pabalan et al. [1] should be explained with caution. To reach a definitive conclusion, well-designed studies with large sample size are required to verify the association between BRIPl polymorphisms and breast cancer risk. We hope that this remark will contribute to more accurate elaboration and substantiation of the results presented by Pabalan et al. [1].

Acknowledgments This work was financially supported by the National Natural Science Foundation of China (No. U1404815).

\section{Conflict of interest None.}

Ethical standards This article does not contain any studies with human participants or animals performed by any of the authors.

\section{References}

1. Pabalan N, Jarjanazi H, Ozcelik H (2013) Association between BRIP1 (BACH1) polymorphisms and breast cancer risk: a metaanalysis. Breast Cancer Res Treat 137:553-558

2. Rutter JL, Smith AM, Davila MR, Sigurdson AJ, Giusti RM, Pineda MA, Doody MM, Tucker MA, Greene MH, Zhang J et al (2003) Mutational analysis of the BRCAl-interacting genes ZNF350/ZBRK1 and BRIP1/BACH1 among BRCA1 and BRCA2negative probands from breast-ovarian cancer families and among early-onset breast cancer cases and reference individuals. Hum Mutat 22:121-128

3. Song H, Ramus SJ, Kjaer SK, Hogdall E, Dicioccio RA, Whittemore AS, McGuire V, Hogdall C, Jacobs IJ, Easton DF et al (2007) Tagging single nucleotide polymorphisms in the BRIP1 gene and susceptibility to breast and ovarian cancer. PLoS One 2:e268

4. Loizidou MA, Cariolou MA, Neuhausen SL, Newbold RF, Bashiardes E, Marcou Y, Michael T, Daniel M, Kakouri E,
Papadopoulos P et al (2010) Genetic variation in genes interacting with BRCA1/2 and risk of breast cancer in the Cypriot population. Breast Cancer Res Treat 121:147-156

5. Garcia-Closas M, Egan KM, Newcomb PA, Brinton LA, TitusErnstoff L, Chanock S, Welch R, Lissowska J, Peplonska B, Szeszenia-Dabrowska N et al (2006) Polymorphisms in DNA double-strand break repair genes and risk of breast cancer: two population-based studies in USA and Poland, and meta-analyses. Hum Genet 119:376-388

6. Guenard F, Labrie Y, Ouellette G, Joly Beauparlant C, Simard J, Durocher F (2008) Mutational analysis of the breast cancer susceptibility gene BRIP1/BACH1/FANCJ in high-risk non-BRCA1/ $B R C A 2$ breast cancer families. J Hum Genet 53:579-591

7. Seal S, Thompson D, Renwick A, Elliott A, Kelly P, Barfoot R, Chagtai T, Jayatilake H, Ahmed M, Spanova K et al (2006) Truncating mutations in the Fanconi anemia $\mathrm{J}$ gene BRIPl are low-penetrance breast cancer susceptibility alleles. Nat Genet 38:1239-1241

8. Vahteristo P, Yliannala K, Tamminen A, Eerola H, Blomqvist C, Nevanlinna H (2006) BACH1 Ser919Pro variant and breast cancer risk. BMC Cancer 6:19

9. Frank B, Hemminki K, Meindl A, Wappenschmidt B, Sutter C, Kiechle M, Bugert P, Schmutzler RK, Bartram CR, Burwinkel B (2007) BRIP1 (BACH1) variants and familial breast cancer risk: a case-control study. BMC Cancer 7:83

10. Silvestri V, Rizzolo P, Falchetti M, Zanna I, Masala G, Bianchi S, Palli D, Ottini L (2011) Mutation analysis of BRIP1 in male breast cancer cases: a population-based study in Central Italy. Breast Cancer Res Treat 126:539-543

11. Huo X, Lu C, Huang X, Hu Z, Jin G, Ma H, Wang X, Qin J, Shen $\mathrm{H}$, Tang J (2009) Polymorphisms in BRCAl, BRCAl-interacting genes and susceptibility of breast cancer in Chinese women. J Cancer Res Clin Oncol 135:1569-1575

12. Ren LP, Xian YS, Diao DM, Chen Y, Guo Q, Dang CX (2013) Further evidence for the contribution of the BRCAl-interacting protein-terminal helicase 1 (BRIP1) gene in breast cancer susceptibility. Genet Mol Res 12:5793-5801 